\title{
APC mutation associated with late onset of familial adenomatous polyposis
}

\author{
J Smith-Ravin, K Pack, S Hodgson, S K S Tay, R Phillips, W Bodmer
}

\begin{abstract}
Familial adenomatous polyposis is an autosomal dominantly inherited disorder. Mutation studies in the corresponding gene (APC) may provide information for predictive tests for persons at risk in affected families. We report here a new mutation in exon 6 (codon 233) of the APC gene and clinical data in a large family with late onset of the disease in most affected persons.
\end{abstract}

\section{(f Med Genet 1994;31:888-890)}

Familial adenomatous polyposis (FAP) is an autosomal dominantly inherited disorder characterised by the development, at an early age, of over 100 adenomatous polyps in the colon. The risk of colon carcinoma in FAP patients is very high and prophylactic colectomy is therefore advocated once the diagnosis has been made. The APC gene was first localised to chromosome $5 \mathrm{q}$ and later isolated. ${ }^{1-3}$ Most of the germline mutations associated with FAP have been shown to be in the first half of exon 15 of the APC gene and they mostly consist of base pair deletions with two hot spots at codons 1061 and 1309. Mutations in other parts of the gene create stop codons or alteration of the reading frame. ${ }^{4-6}$ Here we report a new mutation in exon 6 of the APC gene in one large family, with the phenotypic findings.

\section{Patients and methods}

SAMPLES

Patients were ascertained from the St Mark's Polyposis Registry. DNA was extracted from

Reviewed 11 March 19 Revised version accepted for publication 22 June 1994

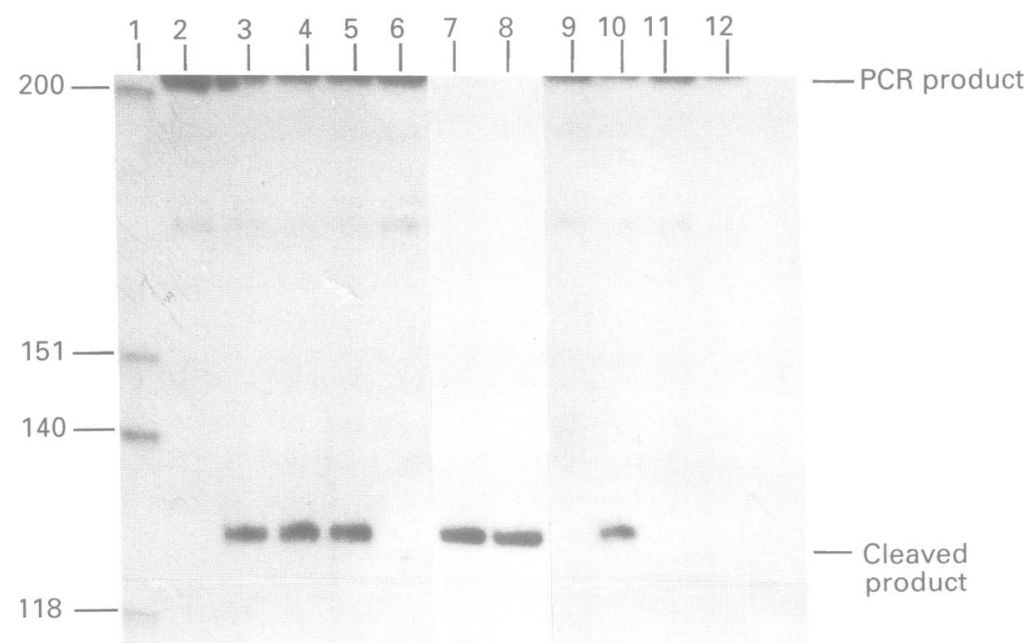

Figure 1 Chemical cleavage mismatch analysis of exon 6. Lane 1: marker $(\phi \times 174$ HinfI); lanes 2 to 12: IV.34, IV.20, V.13, V.14, IV.22, IV.21, IV.10 III.23, IV.12, IV.a, negative control, respectively.
$5 \mathrm{ml}$ of blood using a salt extraction procedure as described elsewhere. ${ }^{7}$ Spouses of persons from the same family were used as controls. Restriction fragment length polymorphism analysis was carried out according to standard procedures. ${ }^{1}$ The number of colonic adenomas at colectomy was derived by extrapolation based on the surface area of excised colon; the polyps were counted per $\mathrm{cm}^{2}$ at a number of sites.

\section{DETECTION OF MUTATIONS}

Exon 6 of the APC gene was amplified with the following primers:

\section{UP: GGTAGCCATAGTATGATTATTTCT ${ }^{2}$ 6RP: CTACCTAT TTT TATACCCACAAAC ${ }^{2}$}

The polymerase chain reaction (PCR) was performed as described by Groden et al. ${ }^{2}$ The amplified product was purified using glass-milk (Bio 101) and the mutation was detected by a chemical cleavage mismatch technique. The method involves the modification, by hydroxylamine, of heteroduplexes between wild type and mutant DNA and their cleavage by piperidine as described elsewhere. ${ }^{8}$ The cleaved product was detected by electrophoresis on a $6 \%$ denaturing gel. Biotinylated PCR product was used in a dideoxy sequencing reaction (Sequenase version $2 \cdot 0$, USB).

\section{Results}

A mutation band at around $130 \mathrm{bp}$ was detected by chemical cleavage mismatch in the affected persons only (fig 1). On sequencing, the mutation was found to be present in codon 233 (fig 2): a substitution of $T$ for $C$, creating a stop codon (Gln to stop). Linkage studies had previously been carried out in this family with DNA markers localised on both sides of the APC gene; all affected subjects shared a common haplotype (fig 3, in bold). The presence of the characterised APC mutation in exon 6 and linkage results were compared for each person under study.

Linkage analysis performed on two different blood samples from subject IV.22 gave him a high predicted risk of being affected on the basis of the results obtained with YN5.48, ECB27, and FB54D, but no adenomas were observed on colonoscopy at 30 years of age. When the mutation was subsequently defined, all the other persons who appeared to be at risk by linkage analysis were found to carry the germline mutation in exon 6, except IV.22. This result was confirmed by sequencing of the 


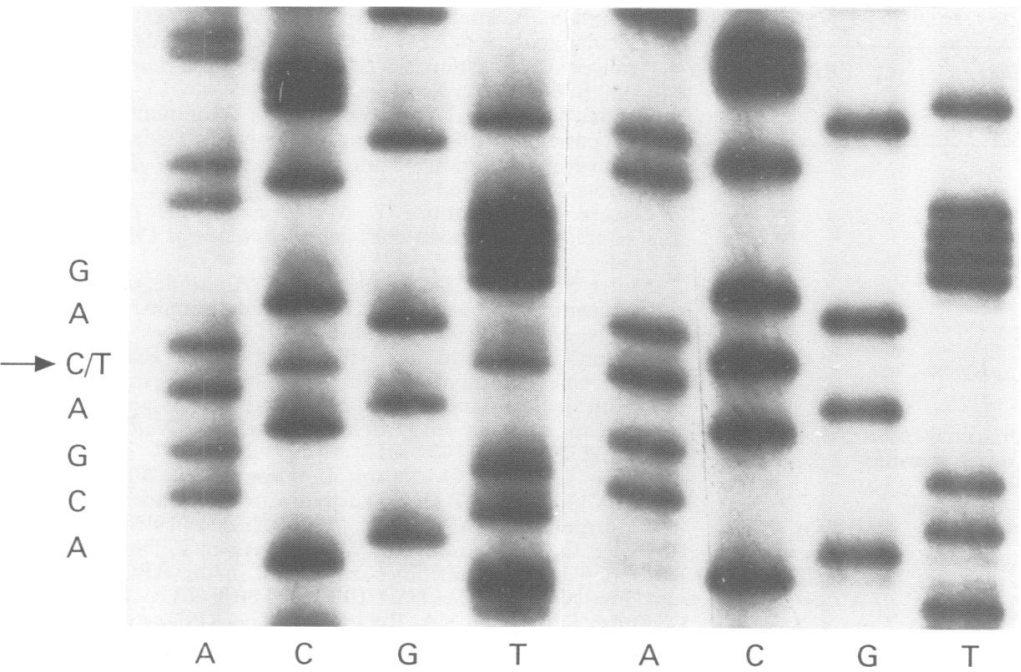

Figure 2 Sequencing analysis of mutation in exon 6 in IV.10 (left) and IV.22 (right). Mutation is indicated by an arrow.

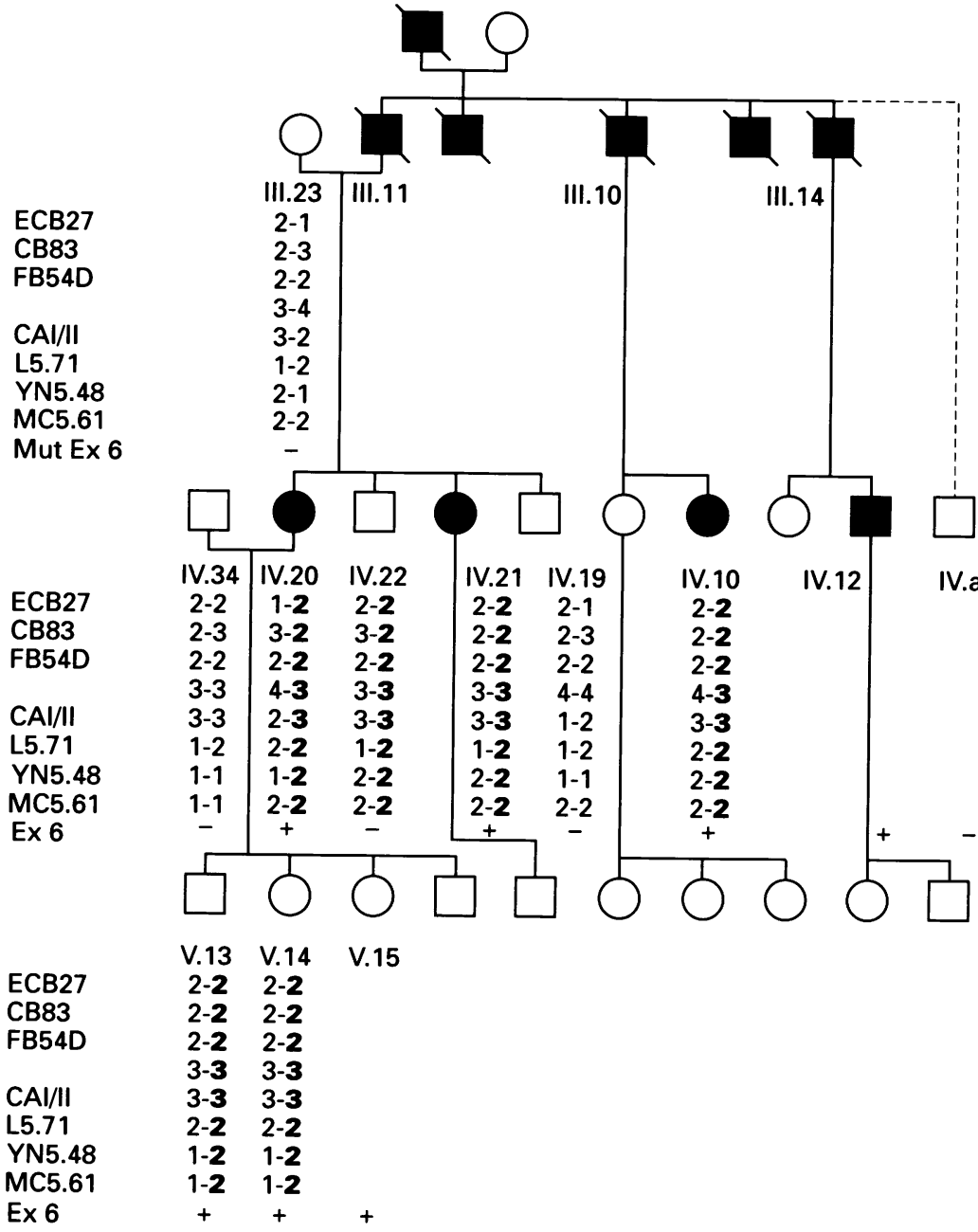

Figure 3 Linkage data showing haplotypes of the polymorphisms using DNA markers close to the APC gene (ECB27, CB83, FB54D, L5.71, YN5.48, MC5.61); CAI/II (DP1) was detected by PCR according to Spirio et al. ${ }^{9}$ Solid symbols: affected persons; open symbols: unaffected or status unknown at the time of study. Affected region is represented in bold. Mutation in exon 6 is described as present $(+)$ or absent $(-)$.

corresponding region (fig 2). The discrepancy is probably the result of non-paternity. IV.12, who showed a mutation in exon 6 , was found to be normal on sigmoidoscopy but presented with multiple sessile polyps on colonoscopy $(0.1$ to $0.2 \mathrm{~cm}$ in diameter).

The clinical results for members of this family are summarised in the table.

\section{Discussion and conclusion}

We have detected a new mutation in exon 6 of the APC gene in persons with FAP in a large family. Mutation analysis confirmed the linkage studies which were previously performed in this family, except in IV.22. For this person, the mutation data were consistent with the colonoscopy examination result. The detection of mutation is therefore a valuable tool for accurately identifying affected persons.

The mutation found in this study is associated with late onset of the disease and rectal sparing. The relatively mild phenotype may be associated with the fact that the mutation is sited more at the $5^{\prime}$ end of the APC gene than the common mutations in exon 15 , resulting in a smaller truncated protein. It has been suggested that a larger, faulty gene product could interfere more by dimerisation with the wild type protein than a protein truncated more proximally. ${ }^{1011}$ Mutations much closer to the $5^{\prime}$ end of the APC gene than the one described here were recently reported by Spirio et $a l^{12}$ in families with an attenuated form of FAP (AAPC). It has also been suggested that modifier genes influence the polyposis phenotype in Min mice ${ }^{13}$ and a similar influence represents another possible explanation for the results reported here. IV.21 was examined for congenital hypertrophy of the retinal pigment epithelium (CHRPE) but none was observed. This is consistent with the findings reported by Olschwang et $a^{14}$ which show that CHRPE lesions are almost always absent when the APC mutation is situated before exon 9 .

Four out of five affected persons in this family presented late with relative rectal sparing of colonic adenomas. However, one affected woman (V.6, not shown in fig 3) was diagnosed at 19 years, when scattered colonic and rectal polyps were detected. Affected subjects in this family have upper gastrointestinal (GI) adenomas, but symptomatic desmoids have not been reported. In all the affected cases, the rectum was either very sparsely involved or not involved at all. Up to now, our clinical practice has been to screen for the FAP phenotype by rigid sigmoidoscopy alone as we have previously felt confident that this will diagnose all cases. The clinical presentation of patients from this family with a mutation in exon 6 of the APC gene has now led us to alter our clinical practice to include colonoscopic surveillance with biopsy when clinically indicated. This is of particular importance considering the variable (and often relatively late) age at onset in different affected persons in this family.

We would like to acknowledge the help of $\mathrm{K}$ Neale, J Landgrebe, and J Mote in the Polyposis Registry, and I Talbot in the Pathology Laboratory, St Mark's Hospital.

1 Bodmer WF, Bailey CJ, Bodmer J, et al. Localisation of the gene for familial adenomatous polyposis on chromosome 5. Nature 1987;328:614-6. 
Summary of clinical results for affected and at risk persons

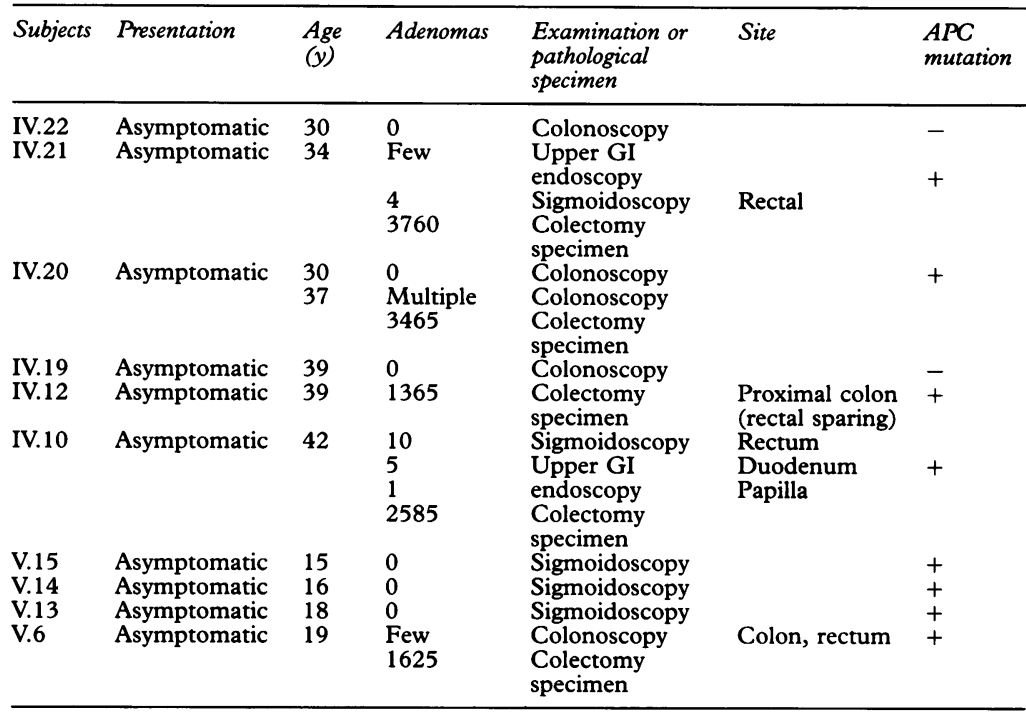

2 Groden J, Thliveris A, Samowitz W, et al. Identification and characterisation of the familial adenomatous polyposis coli gene. Cell 1991;66:589-600.

3 Kinzler KW, Nilbert MC, Su LK, et al. Identification of FAP locus gene from chromosome 5q21. Science 1991; 253:661-5.
4 Cottrell S, Bicknell D, Kaklamanis L, Bodmer WF. Molecular analysis of APC mutations in familial adenomatous polyposis and sporadic colon carcinomas, Lancet 1992; polyposis and

5 Groden J, Gelbert L, Thliveris A, et al. Mutational analysis of patients with adenomatous polyposis: identical inactivating mutation in unrelated individuals. $A m \mathrm{f} \mathrm{Hum}$ Genet 1993;52:263-72.

6 Nagase H, Nakamura Y. Mutations of the APC (adenomatous polyposis coli) gene. Hum Mutat 1993;2:42534

7 Miller SA, Dykes DD, Polesky HF. A simple salting out procedure for extracting DNA from human nucleated cells. Nucleic Acids Res 1988;16:1215.

8 Cotton GHR, Rodriguez NR, Campbell RD. Reactivity of cytosine and thymidine in single-base-pair mismatches with hydroxylamine and osmium teroxide and its application to the study of mutations. Proc Natl Acad Sci USA 1988;85:4397-401.

9 Spirio L, Joslyn G, Nelson L, Leppert M, White R. A CA repeat $30-70 \mathrm{~kb}$ downstream from the adenomatous polyposis coli (APC) gene. Nucleic Acid Res 1991;19:6348.

10 Joslyn G, Richardson DS, White R, Alber T. Dimer formation by an N-terminal coiled coil in the APC protein. ation by an N-terminal coiled coil in the

11 Smith KJ, Johson KA, Bryan TM. The APC gene product in normal and tumour cells. Proc Natl Acad Sci USA 1993;

12 Spirio L, Olschwang S, Groden J, et al. Alleles of the APC gene: an attenuated form of familial polyposis. Cell 1993; 75:951-7.

13 Moser AR, Dove WF, Roth KA, Gordon JI. The Min (multiple intestinal neoplasia) mutation: its effect on gut epithelial cell differentiation and interaction with a modifier system. F Cell Biol 1992;116:1517-26.

14 Olschwang S, Tiret A, Laurent-Puig P, Muleris M, Parc R, Thomas G. Restriction of ocular fundus lesions to a specific subgroup of APC mutations in adenomatous polyposis coli patients. Cell 1993;75:959-68. 